\title{
Heat Transfer Enhancement of a Modularised Thermoelectric Power Generator for Passenger Vehicles
}

\author{
Bo Li ${ }^{1 *}$, Kuo Huang ${ }^{1}$, Yuying Yan ${ }^{1,2 *}{\text { Yong } \mathrm{Li}^{3}, \text { Ssennoga Twaha }}^{1}$, Jie Zhu ${ }^{1}$ \\ ${ }^{1}$ Fluids and Thermal Engineering Research Group, Faculty of Engineering, University of Nottingham, UK \\ ${ }^{2}$ Fluids \& Thermal Engineering Research Centre, University of Nottingham Ningbo, China \\ ${ }^{3}$ School of Automotive and Mechanical Engineering, South China University of Technology, China
}

\begin{abstract}
Transport represents over a quarter of Europe's greenhouse gas emissions and is the leading cause of air pollution in cities. It has not seen the same gradual decline in emissions as other sectors. Recently, the thermoelectric power generation (TEG) technology emerges as an alternative solution to the emission reduction challenge in this area. In this paper, we present an innovative pathway to an improved heat supply into the concentric shape-adapted TEG modules, integrating the heat pipe technologies. It relies on a phase changing approach which enhances the heat flux through the TEG surface. In order to improve the heat transfer for higher efficiency, in our work, the heat pipes are configured in the radial direction of the exhaust streams. The analysis shows that the power output is adequate for the limited space under the chassis of the passenger car. Much effort can also be applied to obtain enhanced convective heat transfer by adjusting the heat pipes at the dual sides of the concentric TEG modules. Heat enhancement at the hot side of the TEG has an effective impact on the total power out of the TEG modules. However, such improvements can be offset by the adjustment made from the coolant side. Predictably, the whole temperature profile of TEG system is subject to the durability and operational limitations of each component. Furthermore, the results highlight the importance of heat transfer versus the TEG power generation under two possible configurations in the passenger car. The highest power output per repeat unit is achieved at $29.8 \mathrm{~W}$ per $0.45 \mathrm{Litre}$ with a ZT value 0.87 for $\mathrm{a} \mathrm{Bi}_{2} \mathrm{Te}_{3}$-based thermoelectric material in our studies. The study provides an insight into a structurally achievable heat exchanger system for other high-temperature thermoelectric materials.
\end{abstract}

Keywords: Thermoelectric power generation, Heat enhancement, Exhaust heat recovery, Temperature-dependent material properties, Heat pipe, Energy harvest

\footnotetext{
*Corresponding author: Bo Li. Email: bo.li@nottingham.ac.uk. Yuying Yan. Email: yuying.yan@nottingham.ac.uk
} 


\section{Introduction}

Thermoelectric heat recovery, as one of the most promising clean technologies, has drawn great attentions due to its unique merits of energy conversion [1]. Unlike the traditional fossil fuel energy systems, TEG devices converts waste heat directly into electricity through the Seebeck effect of the semiconductor materials whereby a temperature difference is maintained between the hot and cold side of the TEG module [2]. The TEG devices have the advantages of silent operation and they have no moving or mechanically complex components enabling them lasting for a very long time. They also operate at wider operational temperature range than most existing energy recovery systems $[3,4]$. There are several existing researches that have proved the feasibility of applying the TEG devices for waste heat recovery from vehicles. Agudelo et al. [5] and Stevens et al. [6] analysed the potential for energy recovery from the exhaust gases and the theoretical limit of thermoelectric generators for a given exhaust system configuration. The results shows that the muffler has the greatest exergy loss making it the ideal place where waste energy can be recovered in the exhaust system. Additionally, there is an optimum number of thermoelectric leg pairs that maximize the power extracted for any TEG system.

However, each technology has its own advantages and challenges. The major challenge of the TEG device is its relatively low heat to electricity conversion efficiency. Recent years have witnessed impressive progress in thermoelectric materials. There have been many researches covering different aspects of thermoelectric materials, including bulk thermoelectric materials, individual nanostructures, and bulk nanostructures [7]. Nonetheless, there is still space for innovation and development of thermoelectric materials to take advantage of their solid-state nature, scalability and environmental friendliness in the automotive industry [8]. It could be highly anticipated from such material development that the TEG system would be applied in automotive waste heat industry in near future, if other challenges are addressed. Furthermore, in practice, the financial viability is highly sensitive to source temperature, device efficiency, maintenance cost, and the projected device lifetime. Benday et al. [9] presented a new methodology for the systematic study of thermoelectric generator economic analysis. This study provided a platform for analysing the performance of real-world systems and can be used to predict where further technological development on TEG materials and devices would be most effective. Huang et al. [10] presented a regenerative concept for TEG systems. It is found that the regenerative TEG systems can achieve power output which is similar with other TEG systems by using high temperature TE materials and guarantee a lower cost. 
Despite the increasing research on thermoelectric materials, there are still many device-level challenges that prevent TEG devices from being applied in real applications. There are many researchers who focus on the numerical simulation of the performance of the TEG devices [11-13]. Hogblom et al. [14] established a simulation methodology for characterization and simulation of TEG systems allowing accurate prediction of the voltage and current as well as the heat flow at steady state. Zhang [15] first developed a numerical model which has taken into account the influence of temperature-dependent material properties, spatial-dependent heat flow rate in thermoelements and the heat and electricity losses at the junctions for performance calculation of the TEG devices. Liang et al. [16] presented a mathematical model of two-stage TEG and the performance of the two-stage TEG is analysed by simulating the effect of relevant factors as well. The results show that the output power and conversion efficiency of the two-stage TEG are higher, compared with the single-stage TEG. Yu et al. [17] investigated the transient behaviour of TEG system in different start-up modes by using the different heat transfer coefficient related to the engine speed. It is concluded that a higher vehicle speed improves the TEG performance in addition to accelerating the transient response. Liu et al. [18] developed an approach for integrating computer-aided analysis with an optimization method that could be applied to the design and optimization of thermoelectric generators. This approach was applied to the multi-objective and multi-parameter optimization of geometric thermoelectric generators to design an optimal structure for TE modules. The results showed that the power outputs of the optimal design were about $5.7 \%, 5.0 \%, 9.4 \%, 18.9 \%, 28.9 \%$, and $30.6 \%$ higher, respectively, than the initial design values. However, the improvement in power output reduced the conversion efficiency.

In addition to the numerical simulation research, there are also several researchers who have investigated the performance of TEG devices by experimental tests. Liu et al. [19, 20] performed experimental study on different structural designs of heat exchanger in order improve the efficiency of TEG system in which a maximum power output of $944 \mathrm{~W}$ is obtained in the revolving drum test under real working condition. Montecucco et al. [21-23] analysed the impact of thermal imbalance on the power produced at module and system level of a TEG array in series and parallel. Experimental results clearly demonstrate that the temperature-mismatch situation creates a power production drop of $9.22 \%$ and $12.90 \%$ for the series and parallel cases respectively. Wang et al. [24] performed a serial experimental test on a new type of open-cell metal foam-filled plate heat exchanger based thermoelectric generator system. The results show that the heat exchange efficiency of $83.56 \%$ between heated air and cold water is achieved.

Other than the progress in the simulation and experimental study of the performance of TEG devices, the heat transfer performance has also been paid close attention. In most cases, it is poor heat transfer design that inhibits achieving the ideal efficiency. Accordingly, thermal scientists and system 
engineers focus mainly on enhancing the heat transfer to and from the TEG devices in order to improve the overall efficiency of the vehicle TEG systems [25]. Beyond the heat transfer enhancement, the novel design of the heat exchanger for TEG devices has been carried out as well. Aranguren et al. [26] built a new thermoelectric generator prototype which could produce $21.56 \mathrm{~W}$ of net energy covering $0.25 \mathrm{~m}^{2}$ of space. In terms of heat dissipation, with the usage of the heat pipes in the finned heat exchanger, a $43 \%$ more net power is obtained. Ma et al. [27] investigated the effect of longitudinal vortex generators (LVGs) on the performance of a TEG with a plate-fin heat exchanger numerically. The results indicated that the heat input and open circuit voltage of the TEG with LVGs are increased by 41-75\% compared to a TEG with smooth channel. Tian et al. [28] proposed a new waste heat recovery system with a heat pipe exchanger which is applied to recover thermal energy in high temperature industrial exhaust gas. After three-month of continuous operation, the heat pipe exchanger is observed to save $15 \%$ natural gas without any blockage of the gas side channel. In addition to the notable TEG performance discussed so far, the existing TEG systems are often too bulky to be applied in the exhaust system. Ali et al. [29] introduced a new innovative design of the thermoelectric generator incorporating the extended pin with segmented pin configuration. The new design allows the device operating at two different cold junction temperatures. Wang et al. [30] presented an innovative design of a cylindrical TEG heat exchanger which is applied to light duty passenger cars. An effective solution for enhancing the heat transfer of gas flow in the radial direction to the TEG is proposed in their research. Huang et al. [31] have investigated the electrical performance between different shapes of TE module, the results indicate that the open circuit electric potential of the annular TE module is $17 \%$ higher than that of the square TE module. Most of the existing researches are based on the numerical and experimental analysis of the influence of external conditions such as temperature and mass flow rate of heat exchanger for exhaust TEG system. However, the installation space and weight of the TEG system are rarely discussed. In practice, there is a very limited space in the vehicle exhaust system and therefore it should be optimized. Moreover, the weight of the TEG is also a vital factor in an effort to achieve the fuel economy [32].

To improve the defects of existing vehicular TEG systems, a light weight heat exchanger is significant for the development of vehicular TEG systems. Therefore, in the current work, a novel design of a concentric cylindrical TEG system is presented for use in the automotive exhaust system. Instead of using a bulky and heavy heat exchanger, the novel TEG system has a compact and lightweight heat sink which is assisted by heat pipes. As a reliable and efficient heat transfer component, heat pipes have been widely used for the thermal management of electronic devices. Heat pipes have the advantageous in that they have high heat conductivity, fast thermal response, 
and are light weight $[33,34]$. The combination of heat pipes with heat exchanger is projected to reduce the weight of the TEG system and the whole vehicle as well, consequently improving the fuel economy.

The proposed design is capable of adapting to the shape of the exhaust pipe besides accommodating more TEMs in the same installation length. In this paper, the numerical studies about the heat transfer performance of this novel TEG system is conducted with different heat transfer coefficient conditions at hot and cold sides of the heat sink. The present study also investigates the impact of heat enhancement at the hot side on the total power out of the TEG modules and the influence of the arrangement of the coolant side. Furthermore, the whole temperature profiles of TEG system in different cross-section and the temperature distribution in the direction of thermoelectric legs are explored in this study. At last, the contour of the maximum power output for the single repeat unit of the TEG system is concluded under different convective heat transfer coefficients on the exhaust gas and coolant side of the system which are correspond to engine speed under different working conditions. Thus, in this study, the feasibility of heat-pipe synergic heat exchanger and the thermal and electric performance of the concentric cylindrical TEG system are examined.

\section{Model description}

A thermoelectric system is composed of several thermal and masses transport processes which store and exchange heat through conduction, convection and radiation. Fig.1 shows the overall architecture of a thermoelectric power generation system in the form of heat energy flow. The TEG is connected with thermal masses on both the hot and cold sides. Energy conversion in the TEG takes place in the form of electrical and heat power, leading to changes in the thermal energy stored inside the thermal masses towards the downstream. Meanwhile, parasitic heat loss is inevitable within the TEG due to the Peltier effect (at interfaces) and resistive Joule heating. In addition to the improvements of TEG ZT value, the heat conduction and convection processes at both sides of TEG module are also the major parameters to maintain the performance of power generation. Regarding the economics of thermoelectric power generation, the cost mainly depends on the nature of the heat source in place whereby adequate heating is needed by the relatively low efficient TEG materials. To develop a thermoelectric system including heat exchangers, heat flux through the thermoelements should be sufficient to maintain the appropriate temperature difference. 


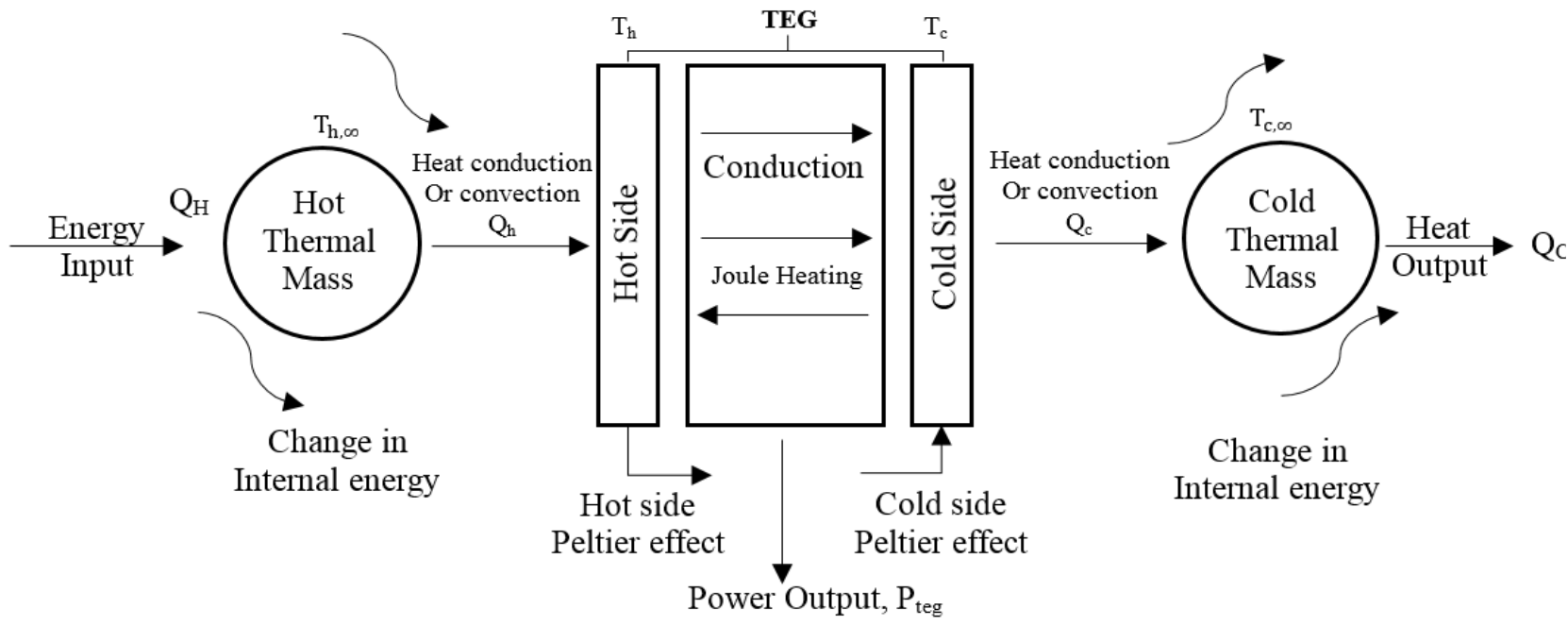

Fig.1. Schematic of a full thermoelectric power generation system with major heat transfer features

The typical heat flux through the thermoelectric legs is maintained at around $10 \mathrm{~kW} / \mathrm{cm}^{2}$, assuming that the legs thickness is $1 \mathrm{~mm}$ and the temperature difference is $373 \mathrm{~K}$. One can potentially deliver this heat flux by concentrating heat through conduction in the device`s hot and cold sides whereby using fins or any other heat transfer enhancement methods are employed. System optimisation, especially for automotive applications, is crucial, hence both the thermoelectric device and the heat exchangers should be developed together to match heat flux requirements. Constantly varying heat source/sink temperatures over hot/cold sides of the thermoelectric modules is also a problem in the exhaust heat recovery system. In a typical exhaust heat recovery system, heat sink/source (usually fluids) temperature varies significantly along the flow direction. Therefore, a proper thermal limiting or flattening component may be needed to solve the heating mismatch along the exhaust pipe. 


\subsection{Schematic structure}

As shown in Fig.2, the TEG system consists of a series of repeat units that are segregated along the exhaust stream to shape into a practical exhaust pipe. The repeat unit is made up of four concentric TEG modules, three hot plates and two cooling plates including twelve heat pipes in each plate as highlighted in blue and red colours in Fig. 2a and Fig. 2b. The exhaust stream interacts with heat pipes and transfers the heat into the TEG in the radial direction of the exhaust stream. The channel spaces of
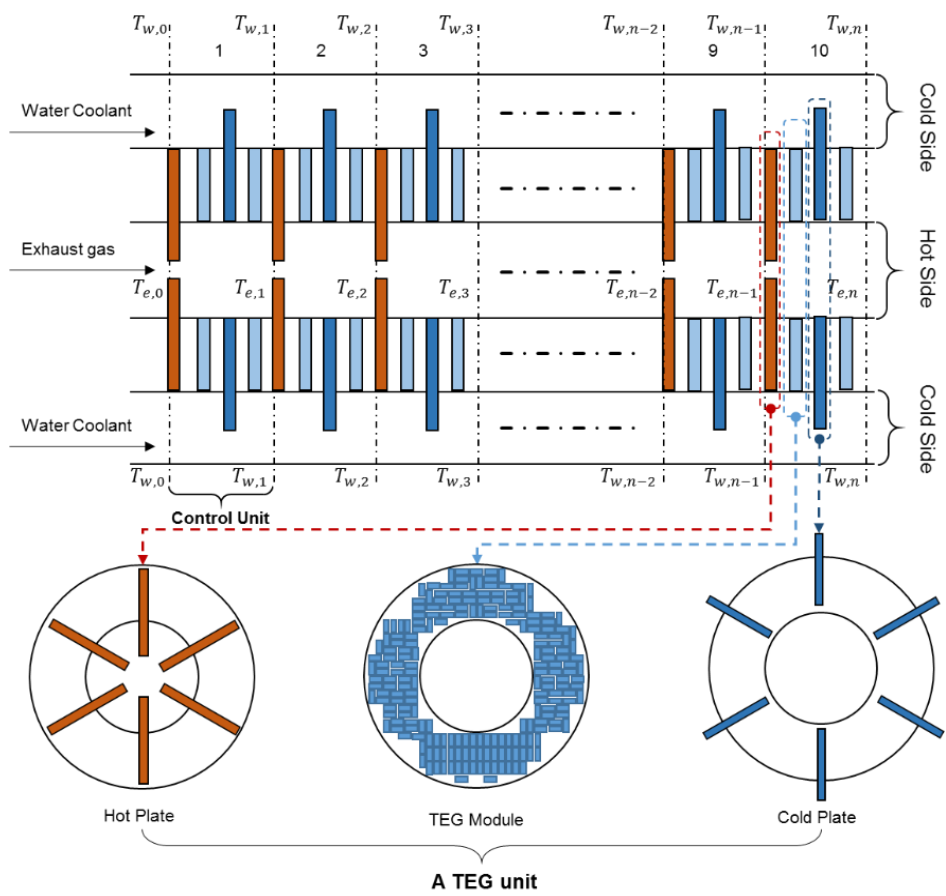

2D simplified model

(a)

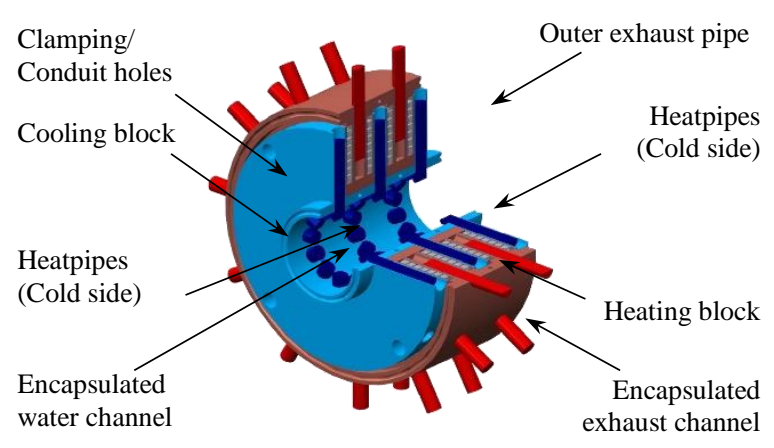

'Cold core' configuration (Water channel inside)

(b)

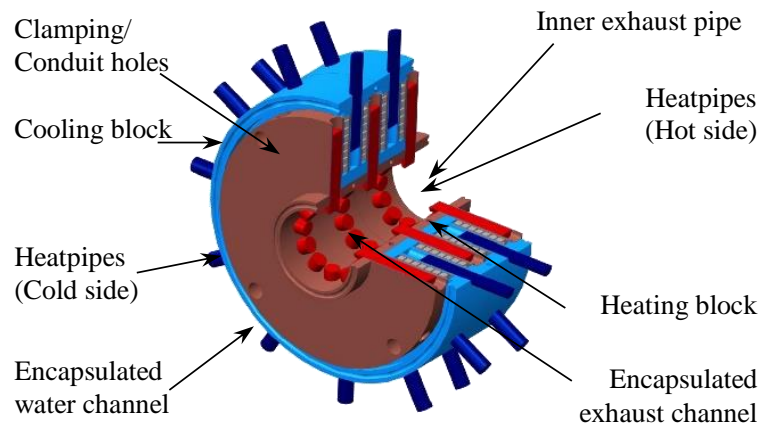

'Hot core' configuration (Exhaust channel inside)

(c)

Fig. 2. A schematic of the (a) 2D TEG system model and the two 3D configurations of hot and cold sources: (b) 'Cold core' configuration and (c) 'Hot core' configuration

both the exhaust and the coolant are tightly shaped by the heat pipes, the surface of the cooling plates and the shell of the heat exchanger. Based on the power output demand, this configuration can be easily adapted by exchanging the channels of the exhaust and coolant flows as well as adjusting the number of repeat units. In reality, each unit has different flow parameters such as coolant temperature $T_{w, n}$, exhaust temperature $T_{e, n}$. These differences arise as a result of decreasing the temperature of the exhaust while increasing the temperature of the coolant. Therefore, the specific configuration of flow patterns makes great impacts on the thermoelectric power generation.

Comparing with some commonly used TEG modules, a concentric TEG module is applied instead of the square-shaped TEG modules, where the method of self-clamping by adjacent TEG modules is introduced to further reduce the need for the single clamp on each TEG modules. In such model, the 
primary assumption of constant temperature in the exhaust and coolant flow is made for simulation purposes. Also, the parallel link inside each repeat unit is set in which the total internal electrical resistance $R_{i n}$ is equal to a quarter of individual TEG module resistance $R_{T E G}$. The parameter analysis of matched load resistance is conducted for tracking the maximum power point when the external load is fluctuating. By assuming the same power output from each unit, the total power generation of the whole system is calculated by multiplying the number of units used in the exhaust pipe.

Specifically, in Fig. 2b, the coolant flow can be allocated to an inner axial flow by replacing the exhaust flow with the outer axial flow channel in respect of utilising the merit of the higher heat capacity of the water coolant. In addition, extruded fin stacks can be installed on heat pipes to enhance heat transfer convection in the exhaust streams. Unlike the conventional square shape TEG modules, the concentric and cylindrically shaped TEGs can easily be accommodated with round exhaust pipes. Due to the alteration of clamping method in this new design, the uneven thermomechanical stress on the components are expected to be minimised by replacing the individual clamps with four simple selflocking metal cables that are bolted through the internal holes of TEG modules. Additionally, the geometric details of major TEG components and heat pipes are listed in the Table 1.

Table 1 Geometric details of major TEG components and heat pipes

\begin{tabular}{|c|c|c|c|c|c|c|c|}
\hline Parameters & $\begin{array}{c}\text { Thermoelectric } \\
\text { leg }\end{array}$ & $\begin{array}{c}\text { Copper } \\
\text { connector }\end{array}$ & Heat pipes & $\begin{array}{l}\text { Ceramic } \\
\text { plate }\end{array}$ & $\begin{array}{c}\text { Insulation } \\
\text { ring }\end{array}$ & $\begin{array}{c}\text { External } \\
\text { copper } \\
\text { plate }\end{array}$ & $\begin{array}{c}\text { Internal } \\
\text { copper } \\
\text { plate }\end{array}$ \\
\hline Length (mm) & 2.55 & 5.8 & - & - & - & - & - \\
\hline Width (mm) & 2.55 & 2.55 & - & - & - & - & - \\
\hline Height (mm) & 2.55 & 0.3 & 40 & 0.7 & 16 & 23.1 & 7 \\
\hline Diameter (mm) & - & - & 6 & - & - & - & - \\
\hline $\begin{array}{c}\text { Inner Diameter } \\
(\mathrm{mm})\end{array}$ & - & - & - & 50.8 & 40.8 & 50.8 & 32.8 \\
\hline $\begin{array}{c}\text { External Diameter } \\
(\mathrm{mm})\end{array}$ & - & - & - & 101.6 & 50.8 & 115.6 & 101.6 \\
\hline
\end{tabular}

\subsection{Materials}

In order to simplify the simulations, some assumptions are made to reduce the computational time. Firstly, the thermal resistance caused by coolant convection is much smaller than the exhaust convective heat transfer. Therefore, the heat transfer coefficient of the cold-water $h_{w}$ is assumed to be a constant value. Also given that the complexity of the exhaust mixer and the combustions, air properties are used as an approximation. The error associated with neglecting the combustion products is usually no more than about $2 \%$ [35]. Table 2 shows the properties of the major components in the TEG system used in the simulations. As the heat pipes used in current work are copper-water heat pipe, 
according to the equivalent thermal properties which is guided by the test results from manufacture, the thermal conductivity in the radial direction which is assumed to be $400 \mathrm{~W} / \mathrm{m} \cdot \mathrm{K}$ (same as copper) and $4000 \mathrm{~W} / \mathrm{m} \cdot \mathrm{K}$ in the axial orientation. This setting is widely used in the engineering for simplifying the simulation calculation though with acceptable accuracies.

Table 2 Materials Properties of major components in the TEG system

\begin{tabular}{cccccc}
\hline Parameters & Copper plate & $\begin{array}{c}\text { Copper } \\
\text { connector }\end{array}$ & Ceramic Plate & Insulation material & Heat pipe \\
\hline $\begin{array}{c}\text { Thermal conductivity } \\
(\mathrm{W} / \mathrm{m} \cdot \mathrm{K})\end{array}$ & 400 & 400 & 180 & 0.022 & $400(\mathrm{Radial})$ \\
& & & $4000($ Axial $)$ \\
\hline
\end{tabular}

The thermal conductivity of heating and cooling plates is set at $400 \mathrm{~W} / \mathrm{m} \cdot \mathrm{K}$. The dielectric material, Aluminium Nitride (AIN) ceramic, whose thermal conductivity is assumed to be $180 \mathrm{~W} / \mathrm{m} \cdot \mathrm{K}$, is designed concentrically to separate the copper plates and the TEG legs. The MicroFoam ${ }^{\circledR}$ insulation material, whose thermal conductivity is set as constant at $0.022 \mathrm{~W} / \mathrm{m} \cdot \mathrm{K}$, is installed to prevent the heat loss between the exhaust and the coolant, This insulation material is used in this case due to its stable thermal performance across the high-temperature range.

The thermometric material Bismuth Telluride $\mathrm{Bi}_{2} \mathrm{Te}_{3}$, which is widely available in the common market, is electrically connected in series. Since the TEG thermal properties highly vary under changing temperature conditions, all the relevant properties are set as temperature-dependent variables as shown in Table 3. The interpolations are used here to estimate the Seebeck coefficient, thermal conductivities, and electrical conductivities of the n-type and p-type thermoelectric legs.

Table 3 Temperature-dependent polynomials of thermoelectric materials properties

\begin{tabular}{cccc}
\hline $\begin{array}{c}\text { Thermoelectric } \\
\text { Leg }\end{array}$ & $\begin{array}{c}\text { Seebeck coefficient, } \alpha \\
(\mathrm{V} / \mathrm{K})\end{array}$ & $\begin{array}{c}\text { Thermal conductivity, } \lambda \\
(\mathrm{W} / \mathrm{m} \cdot \mathrm{K})\end{array}$ & $\begin{array}{c}\text { Electrical conductivity, } \boldsymbol{\sigma} \\
(\mathrm{S} / \mathrm{m})\end{array}$ \\
\hline n-type & $2.0 \times 10^{-13} \mathrm{~T}^{3}+1.0 \times 10^{-9} \mathrm{~T}^{2}-9.0$ & $-4.0 \times 10^{-8} \mathrm{~T}^{3}+5.0 \times 10^{-5} \mathrm{~T}^{2}-$ & $-2.6 \times 10^{-3} \mathrm{~T}^{3}+4.60 \mathrm{~T}^{2}-$ \\
& $\mathrm{x} 10^{-07} \mathrm{~T}+8.0 \times 10^{-6}$ & $2.6 \times 10^{-4} \mathrm{~T}+5.1$ & $2.7 \times 10^{3} \mathrm{~T}+5.8 \times 10^{5}$ \\
p-type & $-3.0 \times 10^{-14} \mathrm{~T}^{3}-3.0 \times 10^{-9} \mathrm{~T}^{2}+2.0$ & $2.0 \times 10^{-7} \mathrm{~T}^{3}-0.20 \times 10^{-4} \mathrm{~T}^{2}+$ & $-2.6 \times 10^{-3} \mathrm{~T}^{3}+4.60 \mathrm{~T}^{2}-$ \\
& $\times 10^{-6} \mathrm{~T}-0.20 \times 10^{-4}$ & $8.0 \times 10^{-4} \mathrm{~T}-7.8$ & $2.7 \times 10^{3} \mathrm{~T}+5.8 \times 10^{5}$ \\
\hline
\end{tabular}

\subsection{Boundary Conditions and heat transfer equation}

Many topologies and shapes of the TEG system have been studied in literature (longitudinal, hexagonal transverse, circular, etc.). However, the basic models of heat transfer are not improved fundamentally. Accordingly, this concentric TEG repeat unit is fully assessed in this paper. Considering the function of TEG, the exhaust heat is needed to be extracted from the heat sinks of the TEG, resulting in exhaust temperature reduction at every repeat unit implying that $T_{e, i}>T_{e, i+1}$, in 
other words, the later TEG performance is lower than the previous one. On the other hand, in the coolant loop, the temperature rise is usually within $3^{\circ} \mathrm{C}$ due to the high mass flow rate. The coolant should be heated by the heat sinks of the TEG, which means $T_{w, i}<T_{w, i+1}$ in the direction of the coolant flow. Considering the cases in this study, it is assumed that the TEG repeat unit share the same hot source and cold source temperature for power output evaluation only. The assumption is not considered in the case of fluid flow simulations. Therefore, the heat extraction by heat pipes per unit due to the power generation can be expressed as;

$\sum_{i=1}^{n} Q_{h}^{i}(t)$

where $\mathrm{i}$ is the number of repeat unit, $\mathrm{n}$ is the number of segregated TEG modules placed in series. And $Q_{h}$ is the useful heat from the exhaust flow which is absorbed by the heat sinks and heat pipes as seen in Fig.1. $Q_{h}$ can be obtained by applying the heat transfer equations under Cauchy boundary condition:

$Q_{h}^{i}(t)=h_{e}^{i} \cdot A_{e}^{i} \cdot\left(T_{e, a v g}^{i}(t)-T_{e}^{i}(t)\right)$

where $h_{e}^{i}, A_{e}^{i}$ and $T_{e}^{i}$ are heat transfer coefficients, interfacial area and surface temperature of hot side heat sinks, respectively. $T_{e, a v g}^{i}$ is the average fluid temperature on the hot side heat exchanger and it is the value used to solve the one-dimensional temperature distribution on each TE module, expressed as;

$T_{e, a v g}^{i}(t)=\left(T_{e, \text { in }}^{i}(t)+T_{e, \text { out }}^{i}(t)\right) / 2$

where $T_{e, \text { in }}^{i}(t)=T_{e, \text { out }}^{i-1}(t)$ and $T_{e, \text { out }}^{i}(t)=T_{e, \text { in }}^{i+1}(t)$, this means that the exhaust inlet temperature $T_{e, i n}^{i}$, at each unit, is depended on the previous exhaust outlet temperature from the upper stream. The outlet temperature $T_{e, \text { out }}^{i}$ subsequently become the inlet boundary condition for the lower streams in turn. The same settings can be applied at the coolant side, the heat that is extracted from exhaust is eventually applied in heating up the coolant which can be expressed as;

$\sum_{i=1}^{n} Q_{c}^{i}(t)=\sum_{i=1}^{n} h_{w}^{i} \cdot A_{w}^{i} \cdot\left(T_{w}^{i}(t)-T_{w, a v g}^{i}(t)\right)$

where $h_{w}^{i}, A_{w}^{i}$ and $T_{w}^{i}$ are heat transfer coefficients, interfacial area and surface temperature of cold side heat sinks, respectively. $T_{w, \text { avg }}^{i}$ is the average fluid temperature on the hot side heat exchanger. Therefore in the $i$ th repeat unit, the power output, $P_{\text {teg }}^{i}$ is obtained by four parallel-linked concentric TEG modules, expressed as; 
$P_{\text {teg }}^{i}=Q_{h}^{i}(t)-Q_{c}^{i}(t)=h_{e}^{i} \cdot A_{e}^{i} \cdot\left(T_{e, a v g}^{i}(t)-T_{e}^{i}(t)\right)-h_{w}^{i} \cdot A_{w}^{i} \cdot\left(T_{w}^{i}(t)-T_{w, a v g}^{i}(t)\right)$

Totally, the power output of the configured system can be summed up as;

$$
P_{t o t}=\sum_{i=1}^{n} P_{\text {teg }}^{i}=\sum_{i=1}^{n}\left(h_{e}^{i} \cdot A_{e}^{i} \cdot\left(T_{e, a v g}^{i}(t)-T_{e}^{i}(t)\right)-h_{w}^{i} \cdot A_{w}^{i} \cdot\left(T_{w, a v g}^{i}(t)-T_{w}^{i}(t)\right)\right)
$$

It is worthwhile to note that both $h_{e}^{i}$ and $h_{w}^{i}$ are local averaged-values which are reciprocally associated with engine load and exhaust conditions. These parameters are not only sound indicators of heat transfer enhancement but also used to identify the type of available enhancement methods. Therefore, in this simulations, the both $h_{e}^{i}$ and $h_{c}^{i}$ are varied from $50 \mathrm{~W} / \mathrm{m}^{2} \cdot \mathrm{K}$ to $1200 \mathrm{~W} / \mathrm{m}^{2} \cdot \mathrm{K}$ and from $1000 \mathrm{~W} / \mathrm{m}^{2} \cdot \mathrm{K}$ to $20000 \mathrm{~W} / \mathrm{m}^{2} \cdot \mathrm{K}$, respectively. In addition, the temperature of the exhaust source and the coolant is set as $823 \mathrm{~K}$ and $323 \mathrm{~K}$, respectively. The parameter analysis of external load resistance, $\operatorname{Rex}$, is carried out by varying the value from $0 \Omega$ to $7.5 \Omega$ at a step of $0.1 \Omega$.

Besides the classical heat transfer equations, the thermoelectric effect is integrated and simulated by using the coupled-field equation as;

$$
\begin{aligned}
& -\vec{\nabla}\left(\left(\sigma \alpha^{2} T+\lambda\right) \vec{\nabla} T\right)-\vec{\nabla}(\sigma \alpha T \vec{\nabla} V)=\sigma\left((\vec{\nabla} V)^{2}+\alpha \vec{\nabla} T \vec{\nabla} V\right) \\
& \vec{\nabla}(\sigma \alpha \vec{\nabla} T)+\vec{\nabla}(\sigma \vec{\nabla} V)=0
\end{aligned}
$$

where $\sigma, \alpha$, and $\lambda$ are the electrical conductivity, Seebeck coefficient and the thermal conductivity of thermoelectric legs, respectively. In order to solve these partial differential equations (PDE) [36], the Weak Form PDE function is coded into a physical model builder in the COMSOL Multiphysics Software. Therefore, a 3D geometry of the repeat unit is discretized, and the coupled solutions can be solved based on the above boundary conditions.

\section{Results and discussion}

\subsection{System performance of repeated TEG unit}

In the simulated cases, the best results of the repeated $\mathrm{Bi}_{2} \mathrm{Te}_{3}$-based TEG unit are shown in Fig. 3 (Parallel linked among the four concentric TEG modules). The major features of the TEG are; matched load voltage, matched load current and matched load power as shown in U-I-P curves of Fig.3b. The matched load voltage is obtained at $4.5 \mathrm{~V}$ when the matched load resistance reaches to $0.7 \Omega$ (which is $\mathrm{R}_{\mathrm{L}} / 4$, a quarter of each modular resistance of $2.8 \Omega$ ). Meanwhile, the maximum output power is achieved at $29.8 \mathrm{~W}$ for the same load resistance condition in which the match load output current is 
6.62A which passes through the terminal connectors. The Water-TEG-Exhaust configuration for the radial direction outperforms the Exhaust-TEG-Water configuration shown in Fig.3d which represents the power rating.

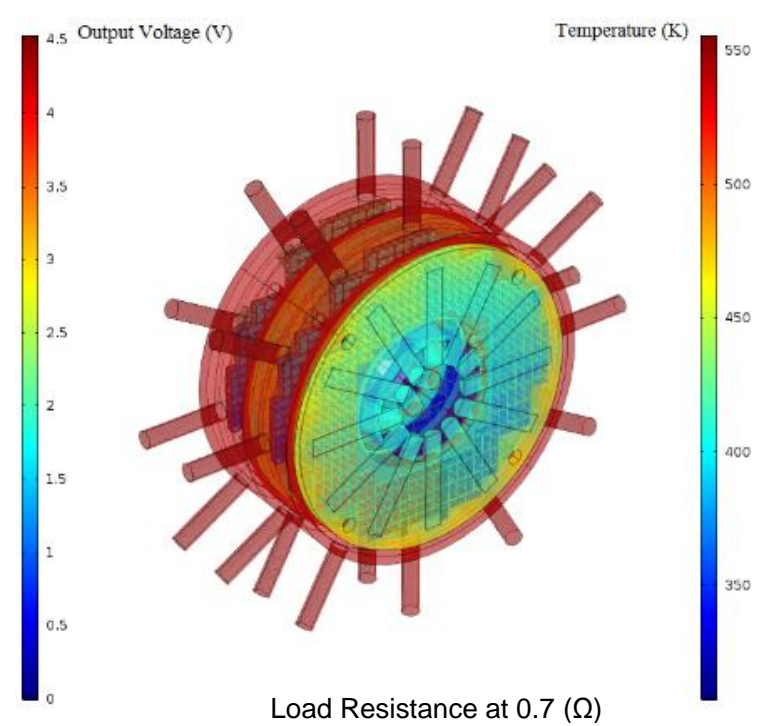

(a)

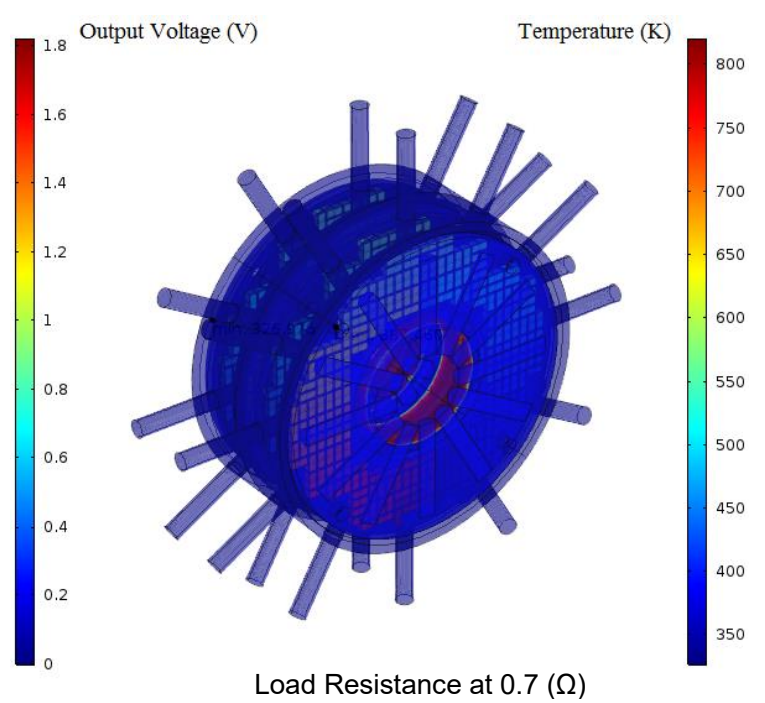

(c)

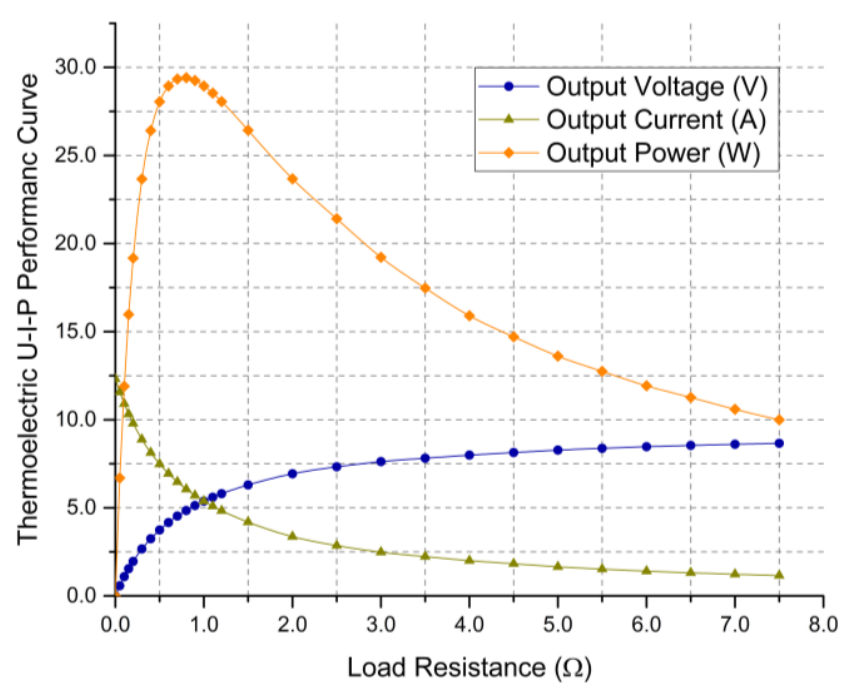

(b)

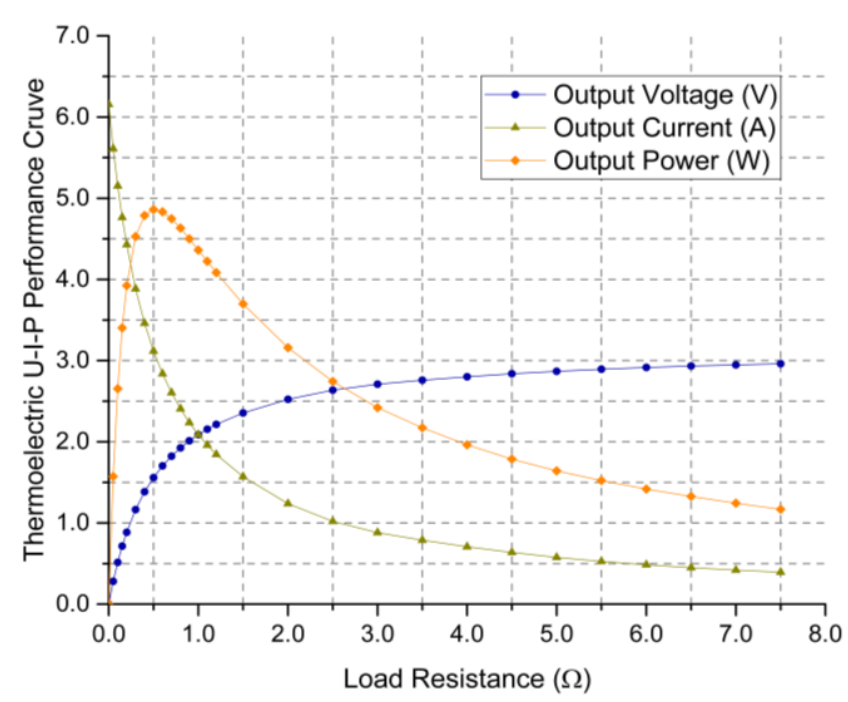

(d)

Fig.3. Repeated TEG temperature distribution simulation at (a) external exhaust channel and (c) internal exhaust channel with matched U-I-V curves at (b) external and (d) intermal exhaust channel configuration respectively

For the Exhaust-TEG-Water configuration, the matched load power achieved is less than $5 \mathrm{~W}$ which is computed for a total of 4 TEG modules even when the best convective conditions are applied. A limited heat transfer area could be the major reason that causes such undesired results. To compare Fig.3a to Fig.3c, the temperature at hot side heat pipe are kept at $555 \mathrm{~K}$ and $371 \mathrm{~K}$ respectively. There 
is still room for improvement to increase the hot side temperature of the TEG legs. However, it should be noted that the fin stacks, which are not simulated in this case, might contribute to higher heat transfer coefficient at the interface of the exhaust and the heat pipes. The main obstacles to applying extra fin stacks are the limited space within the standard exhaust pipe. The advantage of the Water-TEGExhaust configuration is that the fin stacks can easily be applied to the hot side heat pipe at the external channel. Therefore, a higher power rating could be anticipated.

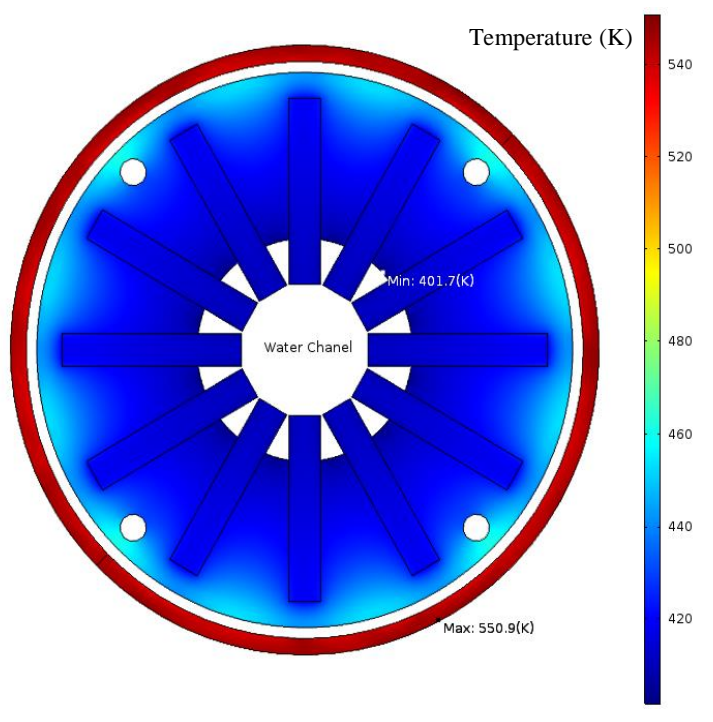

(a)

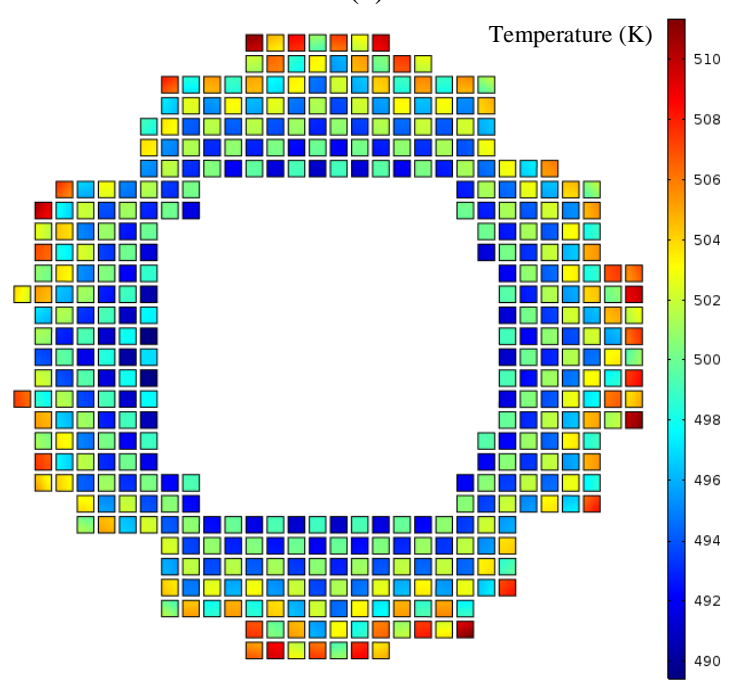

(c)

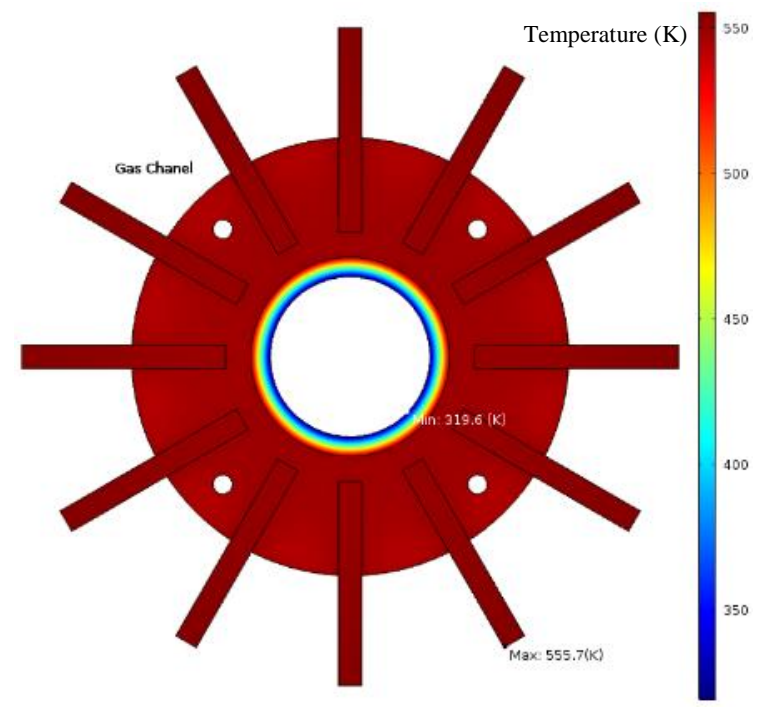

(b)

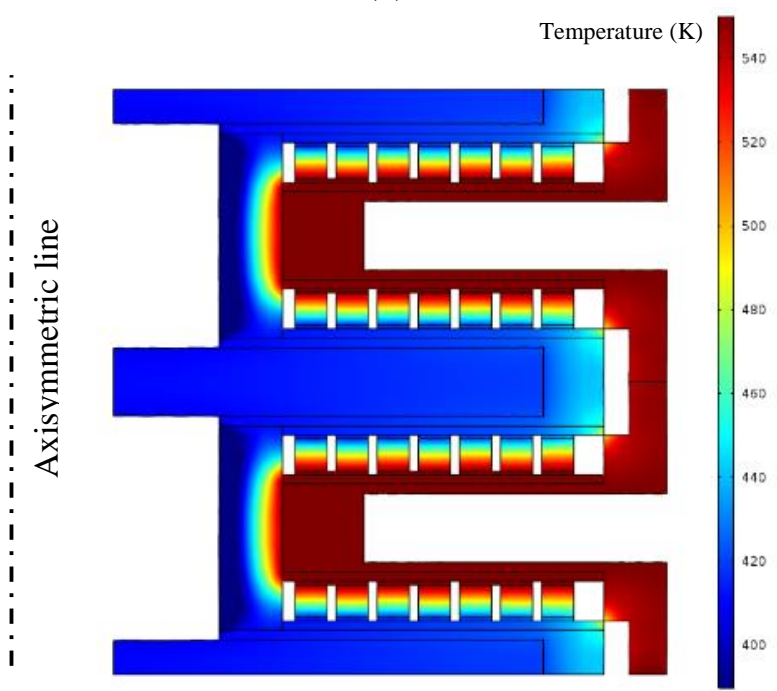

(d)

Fig.4. Thermal performance of thermoelectric power generator system at (a) cooling blocks (b) heating block (c) cross section of TEG modules and (d) the cut out through axisymmetric line

To maintain a sustained temperature difference at both sides of the TEG, heat pipes are deployed in our cases by means of integrating them with the concentric cooling/heating copper blocks. The main reason for such deployment is to reduce the thermal resistance of the heat sinks at both ends of the TEG surfaces. As shown in Fig.4a and Fig.4b, the cooling block can be maintained at $401.7 \mathrm{~K}$ while 
the heating block can be achieved at $555.7 \mathrm{~K}$. Both copper blocks show excellent temperature and even distribution of temperature which help to maintain the temperature of TEG legs within each module. Therefore, a proper temperature distribution within TEG legs can be obtained as seen in Fig.4c where the temperature difference within the module is about $20 \mathrm{~K}$ in the radial direction of the exhaust flow.

In addition to the arrangement of heat pipes, it is worthy to note that proper insulations around the TEG modules also contribute to maintaining a bigger temperature difference as shown in Fig.4d. The thermal bridging may happen without sufficient thermal insulation at the junctions between heating blocks and cooling blocks. This may result in undesirable heat loss to the water coolant directly. As seen in Fig.4d, the TEG modules are tightly sandwiched between stacked cooling and heating blocks. Therefore, thermal insulation material with high performance are required and are carefully placed between the blocks to solve such issues. In this case, the TEG module operates at its optimal temperature condition ranging from $473 \mathrm{~K}$ to $523 \mathrm{~K}$. The figure of merit, ZT value of 0.867 is achieved which is acceptable at the current stage regarding the conversion efficiency.

Due to the unique characteristic of the flow and heat transfer pattern, the correlations of combined internal and external flow correlations (Aligned or staggered tube banks) cannot be applied in this case [37]. Alternatively, the average heat transfer coefficients value $\bar{h}$ at the local interface is adopted as the indicators of heat transfer enhancement.

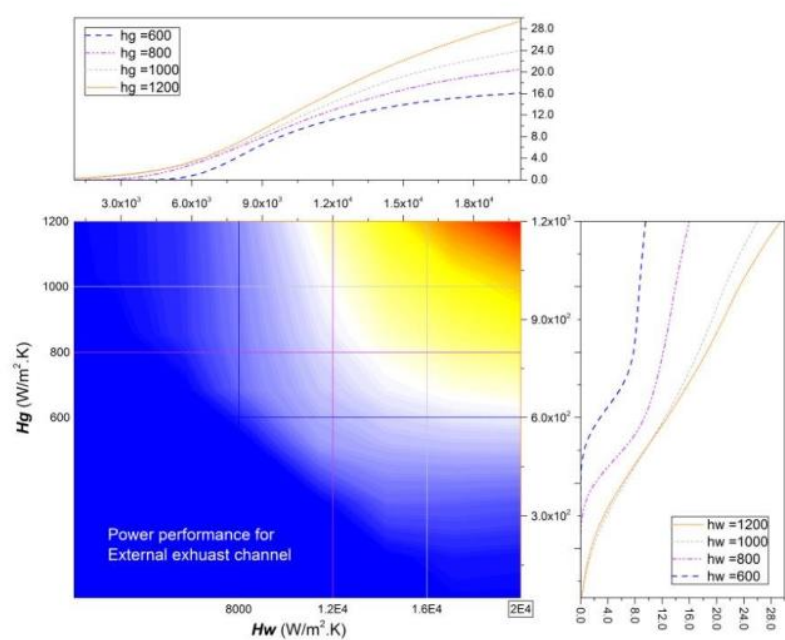

(a)

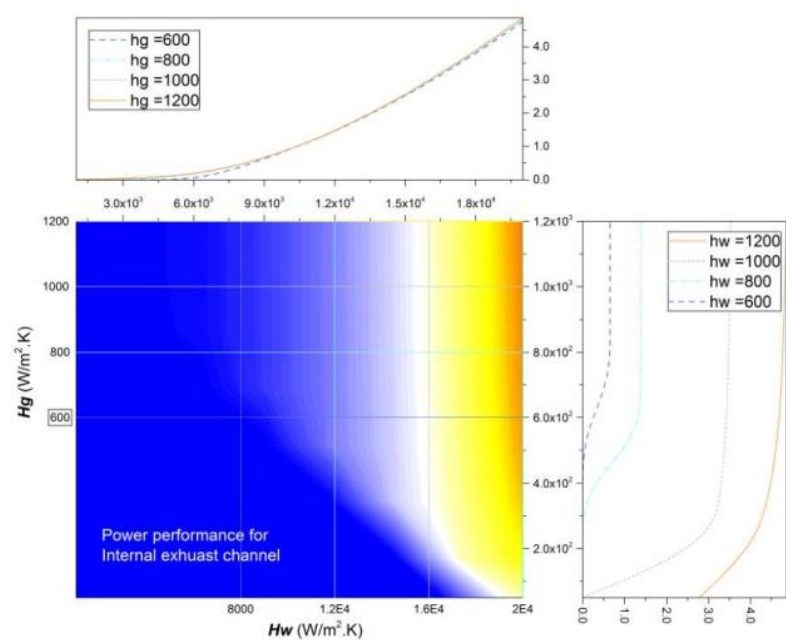

(b)

Fig.5. Power output contour of TEG system under different heat transfer enhancement method for (a) external and (b) internal exhaust channel respectively

As can be seen from the curves of Fig.5a, the increases of heat transfer coefficient of either exhaust gas or coolant reveal a general trend of steady rise of the power output though the margins of the rises varied. And the trends of improvement in power generation could be recognised in two stages from both curves. Below the value of $10000 \mathrm{~W} / \mathrm{m}^{2} \cdot \mathrm{K}$ for the water coolant heat transfer coefficient, the 
power output increase rapidly with coolant side heat enhancement. However, the power out of TEG increases at a slower rate when it comes to the later stage. Same as the water coolant side, there are upward trends in power generation of the TEG, and the curves become more linearly when the heat transfer coefficient increased. In Fig5b, it is noted that the heat transfer enhancement at exhaust side is not effective as expected although the power output increases with higher heat convection. The limited narrow area is the main reason that the waste heat from exhaust is not extracted effectively by the smaller contact area with the heat pipes. However, at water coolant side, the improvements of power output are clearly noticeable. Higher water convection results in improved heat flux through the TEG system and increase the final power output of the repeat unit.

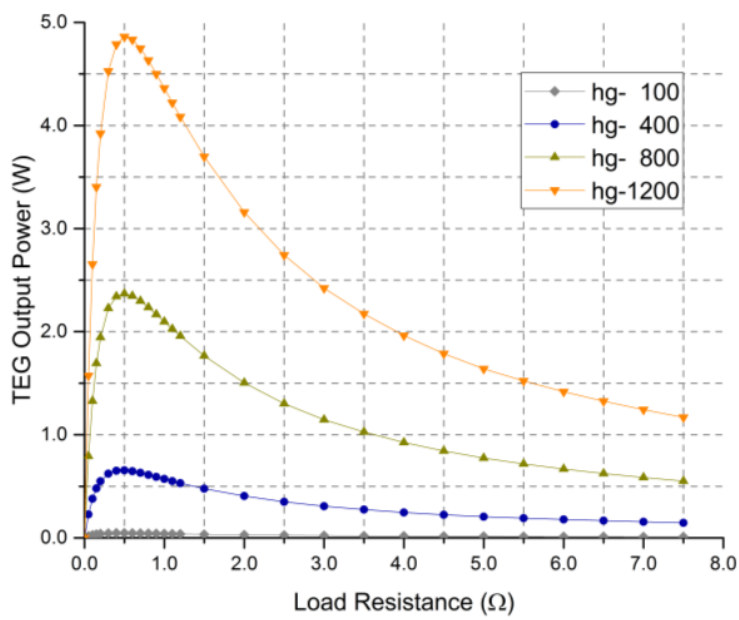

(a)

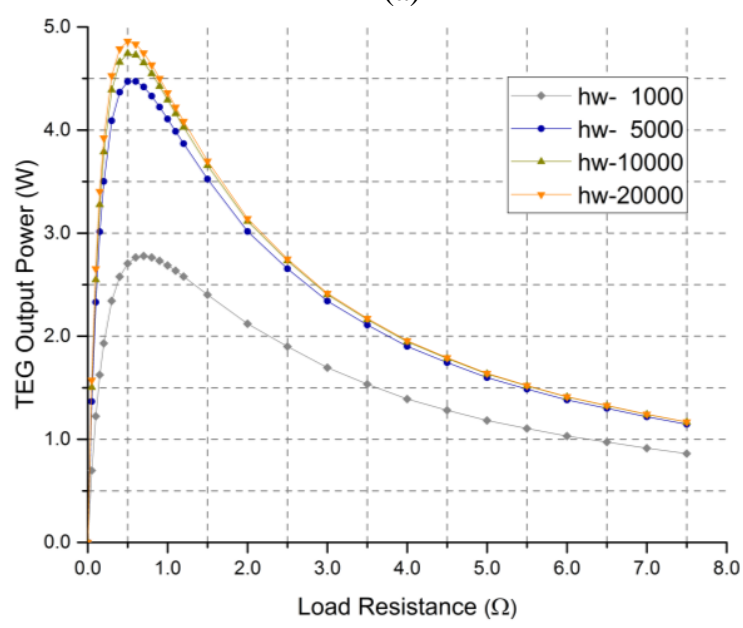

(c)

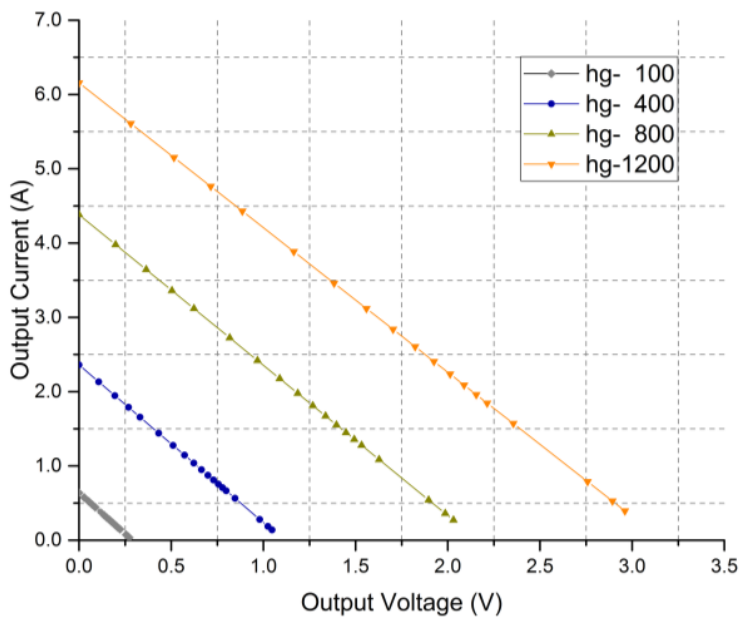

(b)

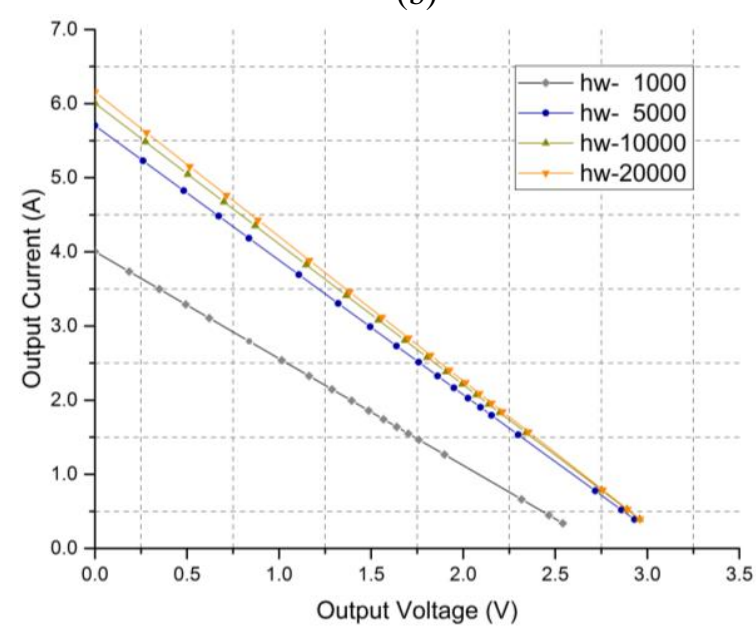

(d)

Fig.6. Performance curves of TEG system with internal exhaust channel: maximum power output versus load resistance and match load voltage versus match load current under enhanced heat convection of (a) and (b) the exhaust gas, (c) and (d) the water coolant 


\subsection{Performance Comparisons}

In the exhaust pipe of modern vehicles, heat transfer coefficient ranges from $100 \mathrm{~W} / \mathrm{m}^{2} \cdot \mathrm{K}$ to 1500 $\mathrm{W} / \mathrm{m}^{2} \cdot \mathrm{K}$ according to the practical engine performance. The exhaust flows steadily in the turbulent region. On the other hand, the heat transfer coefficient of the water coolant in vehicle radiators is in the range of $5000 \mathrm{~W} / \mathrm{m}^{2} \cdot \mathrm{K}$ to $15000 \mathrm{~W} / \mathrm{m}^{2} \cdot \mathrm{K}$ within the fin stacks. Nevertheless, the performance of the TEG is closely related to the layout of the heat source and heat sinks, where careful thermal designs of the TEG heat exchanger should be examined in order to attain better heat transfer performance.

In the radial direction, the heat loss of the conventional exhaust pipe takes place at the pipe surface to the ambient atmosphere. Given that the functions of TEG, the waste heat with high entropy, should be maximally recuperated along the path of exhaust stream flow. In this study, two configurations are simulated and the comparisons between them is discussed. As shown in Fig.6 and Fig.7, both heat source and cold source impose enormous impacts on the output power of the TEGs. However, the overall power rating of the Water-TEG-Exhaust configuration is much better than the Exhaust-TEGWater configuration.

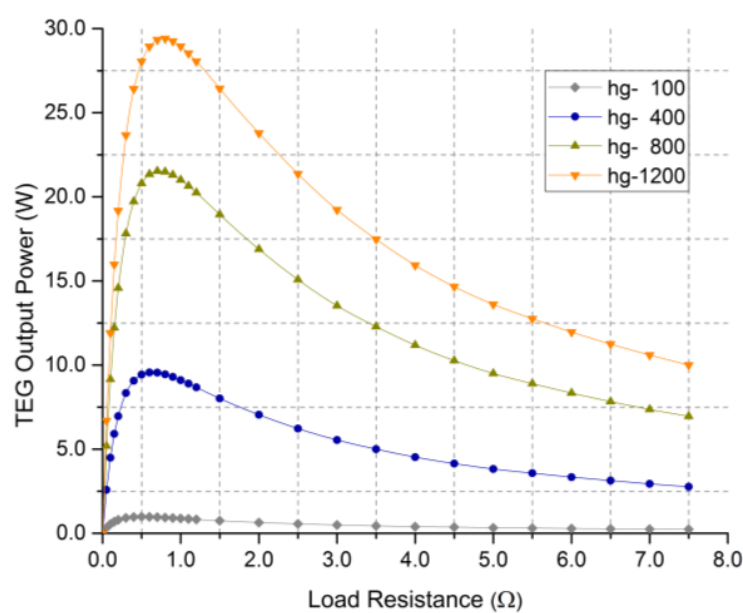

(a)

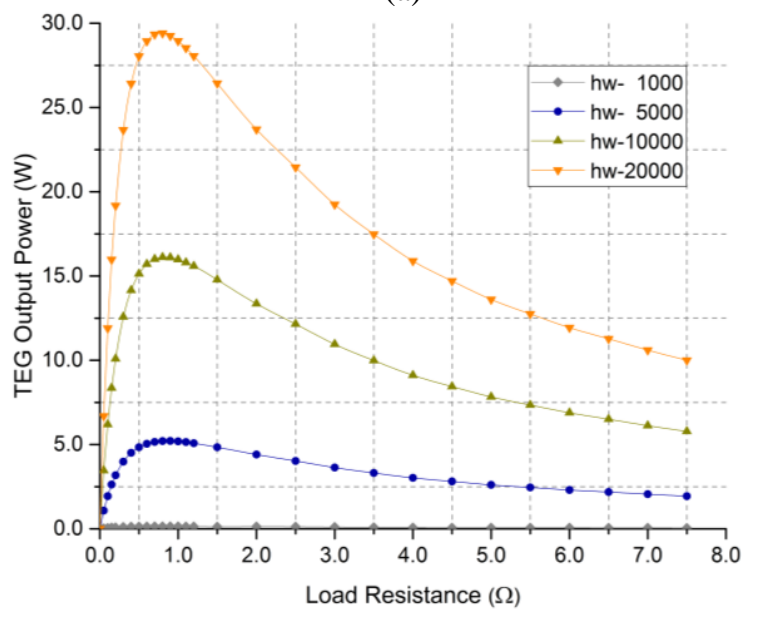

(c)

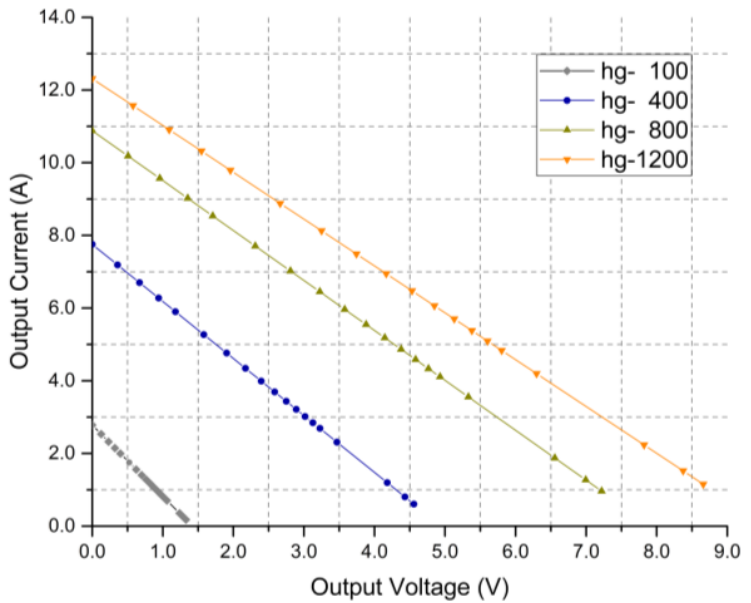

(b)

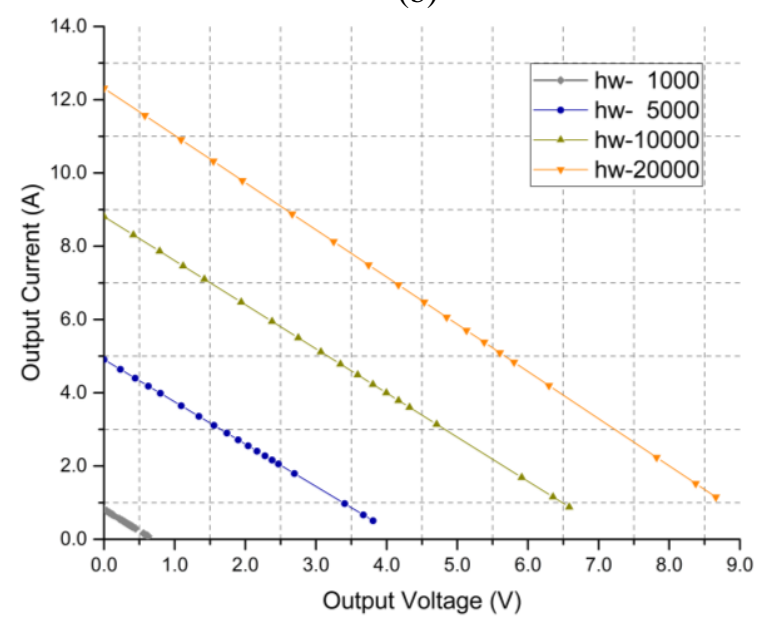

(d) 
Fig.7. Performance curves of TEG system with external exhaust channel: maximum power output versus load resistance and match load voltage versus match load current under enhanced heat convection of (a) and

(b) the exhaust gas, (c) and (d) the water coolant

In Fig.6a, the output power increases significantly with higher heat transfer coefficient. The U-I profile changes correspondingly under the same trend as seen in Fig.6b. Interestingly, the trend in heat transfer improvement at coolant side, which is presented in Fig.6c, shows a disproportional increase in output power for the Exhaust-TEG-Water configuration. Although the output power of the TEG still increases, a weaker impact of higher heat transfer coefficient is noted in Fig.6c and Fig.6d. The growth of both output voltage and output current become inactive as shown in Fig.6d. The resistance of TEG, as presented as the slope of the curves in Fig.6d, are affected by the enhanced coolant flow. The results of U-I curves in Fig.6d tend to be normalised to an upper limit when the heat transfer coefficient increases.

In comparison to with the results of Exhaust-TEG-Water configuration in Fig.6, the Water-TEGExhaust configuration shows better TEG performance in terms of output power, which is consistent with heat transfer coefficient improvement. It is mainly attributed to the larger surface area of the external channel. More heat flux can be transferred into the heating blocks under same heat transfer coefficient conditions. Another main benefit of this setting is that extra fin stacks can be configured on the heat pipes due to the ample space available in the exhaust channel. In such contexts, the higher heat flux can be achieved.

\subsection{Temperature distribution}

The results of temperature distribution in the radial direction of the TEG system are shown in Fig. 8. The two different configurations result in different heating impacts on the components in the TEG system. With the higher heat transfer coefficient at the exhaust channel, the TEG system exhibits a higher temperature profile at the hot side heat pipe. This is consistent with other investigations where a major decline of hot side temperature and temperature gradient are noted in both Fig.8a and Fig.8b due to the parameter variations at the hot side of the TEG module. The largest temperature difference at hot side heat pipe is $225.8 \mathrm{~K}$ while the difference of temperature gradient is maintained at $144 \mathrm{~K}$. This decline inevitably contributes to adverse effects on the power output of the TEG system. Therefore, extra heat enhancement measures are needed in this regard. The optimal temperature of $\mathrm{Bi}_{2} \mathrm{Te}_{3}$ based TEG should settle in the range of $450 \mathrm{~K}$ to $520 \mathrm{~K}$ according to the current material development. Any temperature rise above this region will make TEG legs less efficient and a higher risk of thermal shock to the solder materials. Additionally, the conventional copper-water heat pipe here may be challenged by such temperature rise and therefore could not adhere to the operational 
temperature ranges. As shown in hw-20000-hg-1200 curve of Fig.8a, only such case is suitable for the optimal condition of both the heat pipes and the TEG. The overall temperature profile can be improved and reduced by the application of fins stacks in the future.

On the cold side, the heat transfer coefficient of water coolant has minimal effects on the temperature distribution of the TEG system. It is also noted that the temperature distribution of the exhaust-outside system is generally higher than that of the exhaust-inside system with different heat transfer coefficient, which is well consistent with the previous results in terms of the power output for these two systems. In contrast, the difference of the maximum temperature between these two systems is $104.9 \mathrm{~K}$, but the difference of the maximum temperature between these two systems is merely 2.6 K. Furthermore, the highest temperature gradient of the exhaust-outside system is $300.7 \mathrm{~K}$ which is higher than that of the exhaust-inside system. The reason for such a variance is as a result of the enhanced exhaust heat exchange that is arranged in the external channel.

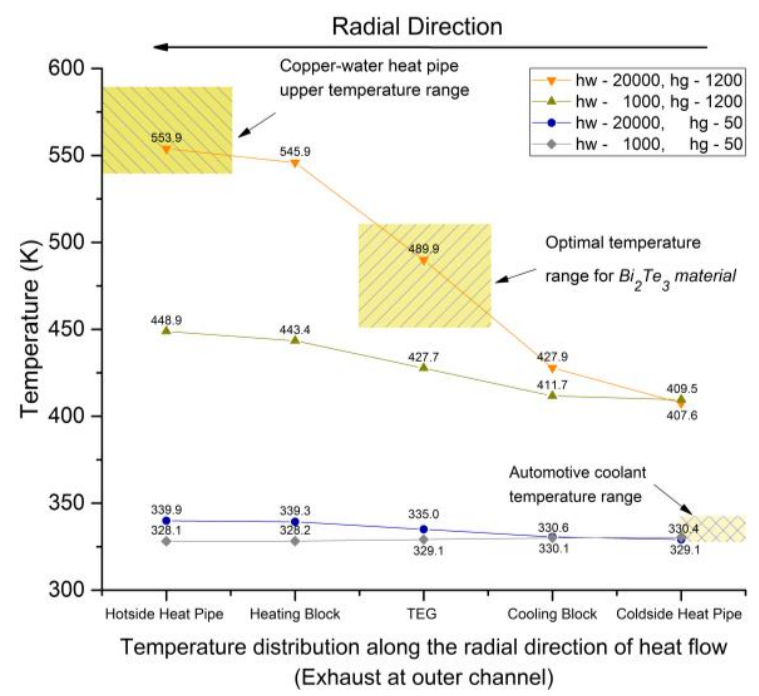

(a)

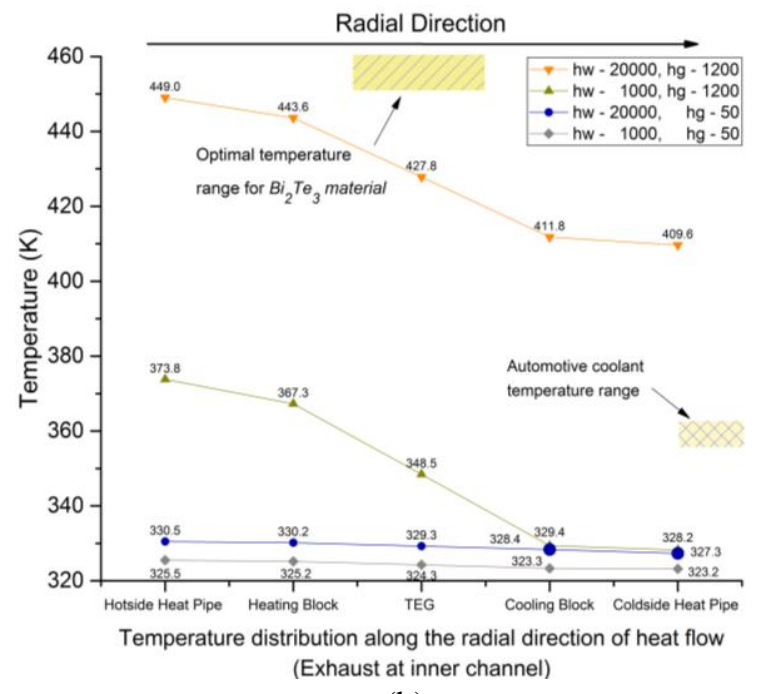

(b)

Fig.8. Schematic of temperature distribution and heat flow across TEG system in radial direction for (a) external and (b) internal exhaust channel

In addition to these four curves in each schematic, there are three shadow parts in these two schematics which indicate the copper-water heat pipe upper-temperature range, including the optimal temperature ranges for $\mathrm{Bi}_{2} \mathrm{TE}_{3}$ material and automotive coolant temperature range. In practice, these three areas are the optimum working temperature for the system when it is assembled in the automotive. Among all these eight curves, it can be noted that the temperature distribution is located at the optimal temperature range for $\mathrm{Bi}_{2} \mathrm{TE}_{3}$ material and copper-water heat pipe upper-temperature range only when the exhaust is arranged at external channel and the heat transfer coefficient when water and exhaust side is set at $20000 \mathrm{~W} / \mathrm{m}^{2} \cdot \mathrm{K}$ and $1200 \mathrm{~W} / \mathrm{m}^{2} \cdot \mathrm{K}$ respectively. In Fig.8b, none of the four curves is located in the optimal temperature range for $\mathrm{Bi}_{2} \mathrm{TE}_{3}$ material in the schematic of the temperature 
distribution of the exhaust-inside system, which means this kind arrangement is not suitable for the concentric cylindrical TEG system, or an enhancement for heat transfer is needed.

This temperature distribution analysis also give a guidance for orientating the concentric cylindrical TEG system in the whole exhaust system in real application. The actual temperature profiles in the TEG should be carefully into account, in order to fit the optimal operational condition for maximum power output of TEG. In addition, it is useful for engineers to seek proper engineering materials and high temperature sealants under all the temperature limits based on our analysis.

\section{Conclusions}

In this paper, a multiphysics model is developed and simulated in multiscale, in which the heat transfer coefficient of the exhaust and the coolant in channels, as well as the heat conduction and electrical conduction in thermoelectric materials, are conjugated and resolved to comprehensible levels. The model is based on an analytical solution of the nonlinear heat transport equation for thermoelectric, which enable it to take into account the temperature-dependent material properties of TE elements. The performance of a novel compact thermoelectric power generation system is studied over a full range of operating parameters regarding the heat transfer enhancements at both the cold and hot sources.

From these results, it can be concluded that

- Heat pipe-assisted heat enhancement method is approved to be an effective way to improve the TEG performance. Encapsulated heat pipes arrays in the radial direction of the exhaust pipe help to enhance heat effectively from an external fluid stream.

- The features of heat pipes such as temperature flattening, temperature control and thermal diode, may help TEG modules for autonomous, maintenance-free operation under fluctuating heating sources in the future. The spatial distribution of the temperature rise is considerately responsive by the variation of heating condition from exhaust streams.

- The electric power generation of the device strongly depends on the heat transfer enhancement.

- The proposed universal structure proved to be useful to systematically provide a broad design and operating parameters that can optimise the device performance and lower its cost.

- The actual temperature profiles analysis give a guidance for orientating the concentric cylindrical TEG system in the whole exhaust system and seeking proper materials in real application.

Endurance test versus performance test is needed in future experiment due to the over limitation of conventional copper-water heat pipes. The cascaded configurations of different types of heat pipes could be a solution which will be validated in our experiment. 


\section{Acknowledgement}

The work is supported by FAW R\&D Centre China and also partially by Ningbo Science and Technology Bureau's Technology Innovation Team Project under Grant No. 2016B10010. We would also like to acknowledge the support from China Scholarship Council (CSC) for the second author's scholarship.

\section{References}

[1] Twaha S, Zhu J, Yan Y, Li B. A comprehensive review of thermoelectric technology: Materials, applications, modelling and performance improvement. Renewable and Sustainable Energy Reviews. 2016;65:698-726.

[2] Bell LE. Cooling, heating, generating power, and recovering waste heat with thermoelectric systems. Science. 2008;321:1457-61.

[3] Karvonen M, Kapoor R, Uusitalo A, Ojanen V. Technology competition in the internal combustion engine waste heat recovery: a patent landscape analysis. J Clean Prod. 2016;112:3735-43.

[4] Singh DV, Pedersen E. A review of waste heat recovery technologies for maritime applications. Energ Convers Manage. 2016;111:315-28.

[5] Agudelo AF, Garcia-Contreras R, Agudelo JR, Armas O. Potential for exhaust gas energy recovery in a diesel passenger car under European driving cycle. Applied Energy. 2016;174:201-12.

[6] Stevens RJ, Weinstein SJ, Kocipula KS. Theoretical limits of thermoelectric power generation from exhaust gases. Applied Energy. 2014;133:80-8.

[7] Tian ZT, Lee S, Chen G. Heat Transfer in Thermoelectric Materials and Devices. J Heat Trans-T Asme. $2013 ; 135$.

[8] Tao C, Chen G, Mu Y, Liu LS, Zhai PC. Simulation and Design of Vehicle Exhaust Power Generation Systems: The Interaction Between the Heat Exchanger and the Thermoelectric Modules. J Electron Mater. 2015;44:1822-33.

[9] Benday NS, Dryden DM, Kornbluth K, Stroeve P. A temperature-variant method for performance modeling and economic analysis of thermoelectric generators: Linking material properties to real-world conditions. Applied Energy. 2017;190:764-71.

[10] Huang SY, Xu XF. A regenerative concept for thermoelectric power generation. Applied Energy. 2017;185:119-25.

[11] He W, Wang SX, Lu C, Zhang X, Li YZ. Influence of different cooling methods on thermoelectric performance of an engine exhaust gas waste heat recovery system. Applied Energy. 2016;162:1251-8.

[12] Massaguer E, Massaguer A, Montoro L, Gonzalez JR. Modeling analysis of longitudinal thermoelectric energy harvester in low temperature waste heat recovery applications. Applied Energy. 2015;140:184-95.

[13] Lee H. Optimal design of thermoelectric devices with dimensional analysis. Applied Energy. 2013;106:79-88.

[14] Hogblom O, Andersson R. A simulation framework for prediction of thermoelectric generator system performance. Applied Energy. 2016;180:472-82.

[15] Zhang T. New thinking on modeling of thermoelectric devices. Applied Energy. 2016;168:65-74.

[16] Liang XY, Sun XX, Tian H, Shu GQ, Wang YS, Wang X. Comparison and parameter optimization of a two-stage thermoelectric generator using high temperature exhaust of internal combustion engine. Applied Energy. 2014;130:190-9.

[17] Yu SH, Du Q, Diao H, Shu GQ, Jiao K. Start-up modes of thermoelectric generator based on vehicle exhaust waste heat recovery. Applied Energy. 2015;138:276-90.

[18] Liu ZC, Zhu SP, Ge Y, Shan F, Zeng LP, Liu W. Geometry optimization of two-stage thermoelectric generators using simplified conjugate-gradient method. Applied Energy. 2017;190:540-52.

[19] Ali H, Yilbas BS, Al-Sharafi A. Innovative design of a thermoelectric generator with extended and segmented pin configurations. Applied Energy. 2017;187:367-79.

[20] Liu X, Deng YD, Zhang K, Xu M, Xu Y, Su CQ. Experiments and simulations on heat exchangers in thermoelectric generator for automotive application. Appl Therm Eng. 2014;71:364-70.

[21] Liu X, Deng YD, Li Z, Su CQ. Performance analysis of a waste heat recovery thermoelectric generation system for automotive application. Energ Convers Manage. 2015;90:121-7.

[22] Montecucco A, Knox AR. Accurate simulation of thermoelectric power generating systems. Applied Energy. 2014;118:166-72.

[23] Montecucco A, Siviter J, Knox AR. Constant heat characterisation and geometrical optimisation of thermoelectric generators. Applied Energy. 2015;149:248-58.

[24] Montecucco A, Siviter J, Knox AR. The effect of temperature mismatch on thermoelectric generators electrically connected in series and parallel. Applied Energy. 2014;123:47-54.

[25] Wang TC, Luan WL, Wang W, Tu ST. Waste heat recovery through plate heat exchanger based thermoelectric generator system. Applied Energy. 2014;136:860-5. 
[26] Wang YP, Li SA, Zhang YF, Yang X, Deng YD, Su CQ. The influence of inner topology of exhaust heat exchanger and thermoelectric module distribution on the performance of automotive thermoelectric generator. Energ Convers Manage. 2016;126:266-77.

[27] Aranguren P, Astrain D, Rodriguez A, Martinez A. Experimental investigation of the applicability of a thermoelectric generator to recover waste heat from a combustion chamber. Applied Energy. 2015;152:121-30.

[28] Ma T, Lu X, Pandit J, Ekkad SV, Huxtable ST, Deshpande S, et al. Numerical study on thermoelectric-hydraulic performance of a thermoelectric power generator with a plate-fin heat exchanger with longitudinal vortex generators. Applied Energy. 2017;185:1343-54.

[29] Tian E, He Y-L, Tao W-Q. Research on a new type waste heat recovery gravity heat pipe exchanger. Applied Energy. 2017;188:586-94.

[30] Wang XZ, Li B, Yan YY, Liu S, Li J. A study on heat transfer enhancement in the radial direction of gas flow for thermoelectric power generation. Appl Therm Eng. 2016;102:176-83.

[31] Huang K, Li B, Yan YY, Li Y, Twaha S, Zhu J. A comprehensive study on a novel concentric cylindrical thermoelectric power generation system. Appl Therm Eng. 2017;117:501-10.

[32] Peng ZJ, Wang TY, He YL, Yang XY, Lu LP. Analysis of environmental and economic benefits of integrated Exhaust Energy Recovery (EER) for vehicles. Applied Energy. 2013;105:238-43.

[33] Li Y, Li ZX, Zhou WJ, Zeng ZX, Yan YY, Li B. Experimental investigation of vapor chambers with different wick structures at various parameters. Exp Therm Fluid Sci. 2016;77:132-43.

[34] Li Y, Zhou WJ, He JB, Yan YY, Li B, Zeng ZX. Thermal performance of ultra-thin flattened heat pipes with composite wick structure. Appl Therm Eng. 2016;102:487-99.

[35] Jääskeläinen H. Diesel Exhaust Gas. https://www.dieselnet.com/tech/diesel_exh.php. [Access Date: 16-Dec-2016]

[36] Jaegle M. Multiphysics Simulation of Thermoelectric Systems - Modeling of Peltier-Cooling and Thermoelectric Generation. COMSOL Conference 2008 Hannover. Hannover2008.

[37] Kandylas IP, Stamatelos AM. Engine exhaust system design based on heat transfer computation. Energy Conversion and Management. 1999;40:1057-72. 